\title{
Design and Simulation of Synchronous Buck Converter in Comparison with Regular Buck Converter
}

\author{
Hossein Zomorodi ${ }^{1,}{ }^{*}$, Erfan Nazari ${ }^{2}$ \\ Department of Electrical and Computer Engineering, Islamic Azad University, Saveh, Iran \\ ${ }^{1}$ h_zomorodi4460@yahoo.com; ${ }^{2}$ erfannazari1986@gmail.com \\ * corresponding author
}

\section{ARTICLE INFO}

\section{Article history}

Received December 19, 2021

Revised January 10, 2022

Accepted January 25, 2022

\section{Keywords}

Low power application;

Conventional buck converter;

Synchronous buck converter;

Switching losses

\begin{abstract}
In a variety of low-power applications, a step-down dc-dc converter is used to reduce the voltage from a higher level. The two types of dc-dc converters are a regular buck and synchronous buck. The synchronous buck utilizes two switches and one diode, whereas the regular buck uses one switch and one diode. Many converters rely on the power components' switching qualities to work. A second MOSFET is required due to the diode's higher conduction losses. Because of the diode's conduction losses, the converter's efficiency may be reduced. The use of a synchronous buck converter improves efficiency by reducing diode losses. The main goal of this study is to compare and contrast these two low-power step-down converters. The simulation in this work was performed using the LTSPICE program.
\end{abstract}

This is an open-access article under the CC-BY-SA license.

\section{Introduction}

Nowadays, power electronics play a very significant role in each part of the electrical system [1]. There are quite a few devices that work by low dc voltage. For instance, in each computer, there are so many parts that require low voltage between $1 \mathrm{~V}$ to $10 \mathrm{~V}$ [2]. The output voltage of the power grid is $\mathrm{AC}$ voltage. Therefore, there is a need to convert AC voltage to DC. Then, after converting $120 \mathrm{~V}$ ac to dc, for reducing the voltage, a step-down dc-dc converter is utilized [3][4][5]. A step-down converter contains some semiconductor components and some other components [6]. Each dc-dc has at least one or two capacitors, one inductor, one switch, and one diode. However, in some buck converters, in order to reduce the losses of the diode, a second switch is used instead of the diode, which is known as a synchronous dc-dc converter [7]. A buck converter is a step-down converter that successfully lowers the voltage level to meet the needs of the low power application [8][9]. As a result, a synchronous buck converter is presented to attain great efficiency. When a MOSFET replaces a diode, the voltage drop will go from $0.7 \mathrm{~V}$ to $0.2 \mathrm{~V}$. As a result, the converter's efficiency is increased [10]. Fig. 1 shows a regular buck converter.

According to Fig. 1, a regular buck contains one MOSFET, one diode, one inductor, and two capacitors [11]. This paper compares the regular buck with a synchronous buck [12]. The simulation results indicated that the output power of the synchronous buck is higher than the regular buck owing to the fact that the power losses of the diode will be eliminated, and therefore there is more power [13][14]. Several types of research about designing power converters have been done. In [15], the author investigated switched quadratic capacitor converter in order to reach the wide stepping down. Also, ref. [16] shows the effects of using common source inductance to reduce power losses. Authors 
in [17] proposed an idea of resonant approach to decrease the output losses dramatically. In [18], the author utilized laterally double-MOSFET to optimize the circuit performance and finally reduce the power losses. Main goal of the research is to lower the power losses when using power converters. The paper structure is Introduction, Synchronous step down DC-DC converter, Simulation result, and Conclusions.

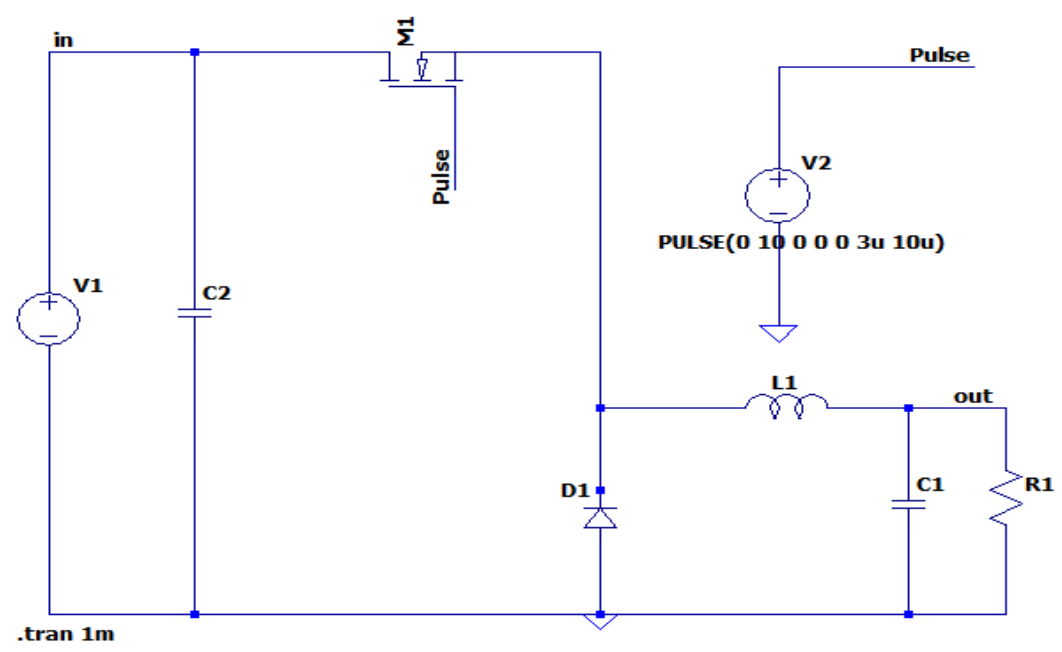

Fig. 1. Regular step down dc-dc converter

\section{Synchronous Step-Down DC-DC Converter}

Asynchronous buck converter uses another switch instead of the diode, as can be seen from Fig. 2. In some step-down converters, for the two switches, two IGBTs are utilized. However, in this paper, two MOSFETs are used for the design and also simulation [19][20].
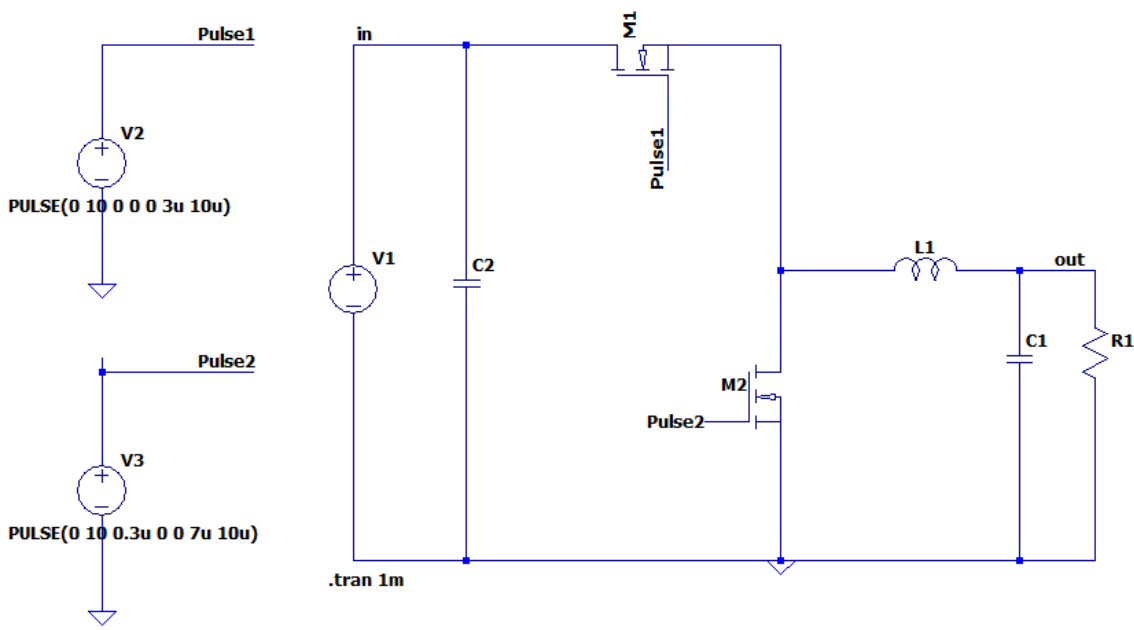

Fig. 2. Synchronous step-down DC-DC Converter

The most crucial aspect of creating a voltage converter is selecting the appropriate components [21][22]. The MOSFETs in this study have a rated dc voltage of $30 \mathrm{~V}$. The rated voltage must be $20 \%$ higher than the input voltage, according to a rule of thumb [23]. Fig. 2 depicts the design of a synchronous step-down. A converter's primary components are two MOSFETs, one inductor, and one output capacitor. The synchronous buck converter must be run in continuous current mode since the MOSFET would allow the inductor current to go negative. The current in the inductor constantly flows in continuous conduction mode. The synchronous buck has two different modes of operation and control system [24][25][26]. The energy from the DC source will charge the inductor and also 
feed the output in the first mode since switch 1 is on and switch 2 is off. When switch 1 is off and switch 2 is on in the second mode of operation, the inductor's stored energy feeds the load and is discharged through switch 2 [27][28]. Eqs. (1), (2), and (3) will be utilized to construct the step-down where $\mathrm{D}$ is the duty ratio and $\Delta V_{o}$ is the output voltage ripple.

$$
\begin{aligned}
& \text { Dutycycle }=\frac{V_{\text {out }}}{V_{\text {in }}} \\
& L=\frac{D T_{s}\left(V_{\text {in }}-V_{\text {out }}\right)}{2 I_{o}} \\
& C=\frac{V_{o} T_{S}(1-D) T_{S}}{8 L \Delta V_{o}}
\end{aligned}
$$

\section{Results and Discussion}

The characteristics of the system are shown in Table 1.

Table 1. Characteristics of the buck converter

\begin{tabular}{|c|c|}
\hline Components & values \\
\hline Vin & $10 \mathrm{~V}$ \\
\hline Vout & $3 \mathrm{~V}$ \\
\hline Inductor & $70 \mu$ \\
\hline Capacitor & $25 \mu$ \\
\hline Switching frequency & $100 \mathrm{kHz}$ \\
\hline Duty cycle & $30 \%$ \\
\hline Rated voltage of the switch and diode & $30 \mathrm{~V}$ \\
\hline
\end{tabular}

\subsection{Simulation Results of the Regular Buck}

Needless to mention that in the regular buck, a diode is used to make a path for discharging the inductor [29][30]. The output voltage and current of the conventional buck are shown in Fig. 3.

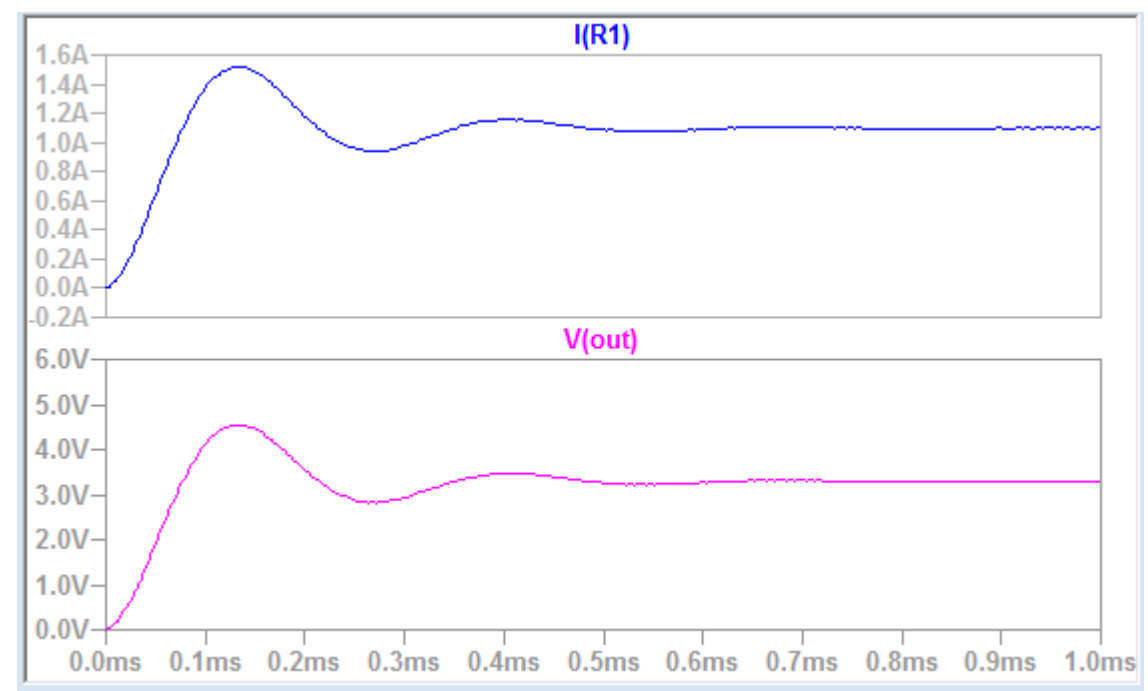

Fig. 3. Output voltage and current

As we can see from Fig. 3, the output generated voltage is $3 \mathrm{~V}$ and the output generated current is $1 \mathrm{~A}$. therefore, the output power is near 3 watts. The voltage and current across the MOSFET (switch) are indicated in Fig. 4. 


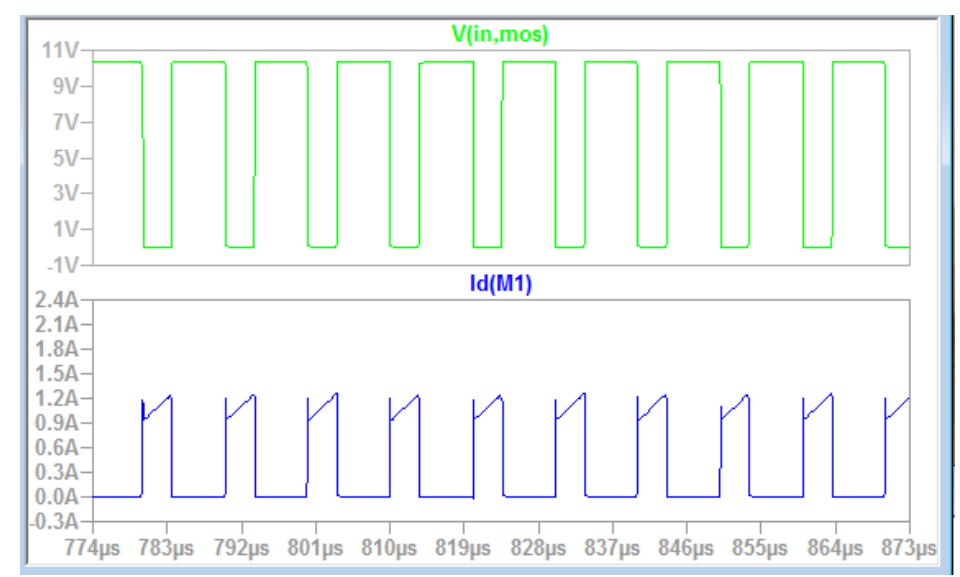

Fig. 4. Voltage and current waveform across the switch

According to Fig. 4, when the switch is on, the voltage across the switch is zero, and the current across the MOSFET is $1 \mathrm{~A}$. Also, when the switch is off, the voltage across the MOSFET is equal to the input voltage. The voltage and current across the diode are shown in Fig. 5.

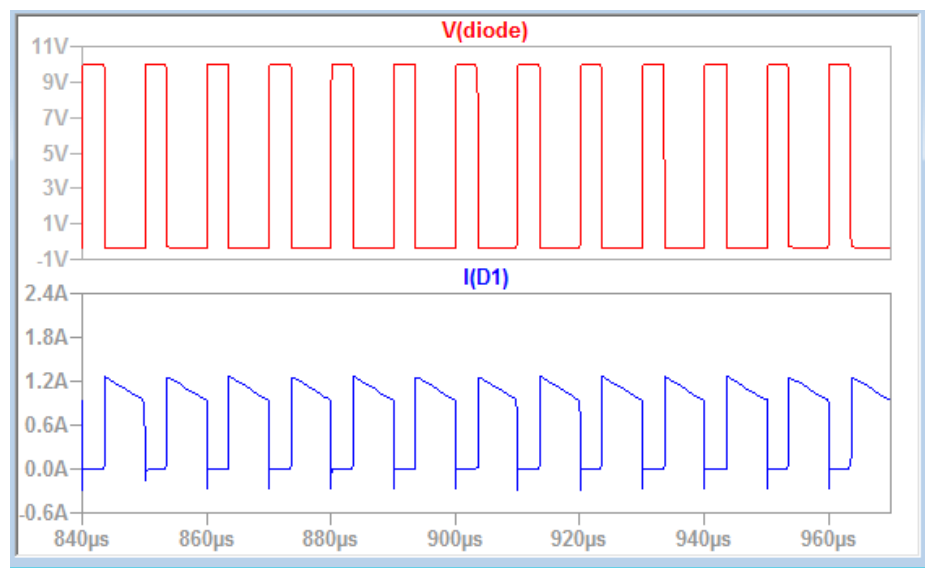

Fig. 5. Voltage and current through the diode

Based on Fig. 5, when the diode is on the forward bias, the voltage across the diode is zero, and the current across it is $1 \mathrm{~A}$. Also, when the diode is on the reverse bias, the voltage across the diode is 10 V. Fig. 6 describes the current through the inductor L1.

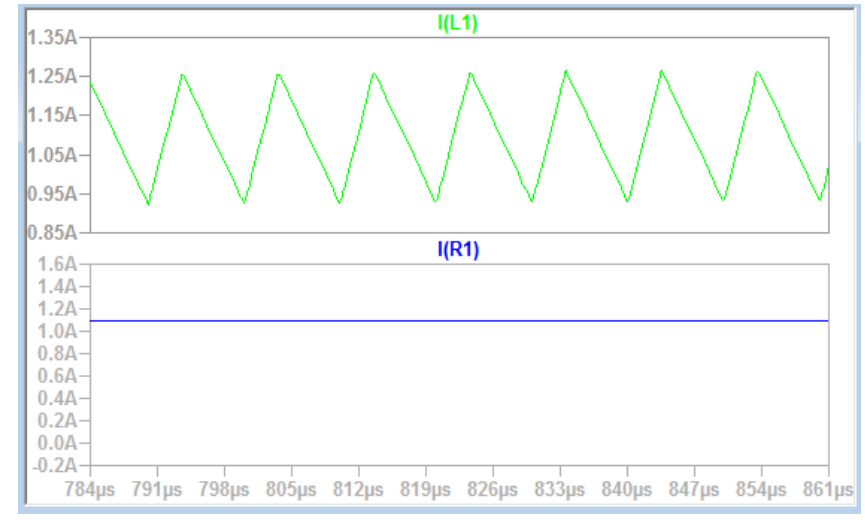

Fig. 6. Inductor current

Based on Fig. 6, the whole system is in continuous conduction mode (CCM) because the peak-topeak inductor current is higher than zero all the time. 


\subsection{Simulation results of the synchronous buck}

It is obvious that in the synchronous buck, there are two switches instead of using one switch and one diode. Both switches in this paper are MOSFETs. The voltage across both switches of the synchronous buck converter is shown in Fig. 7.

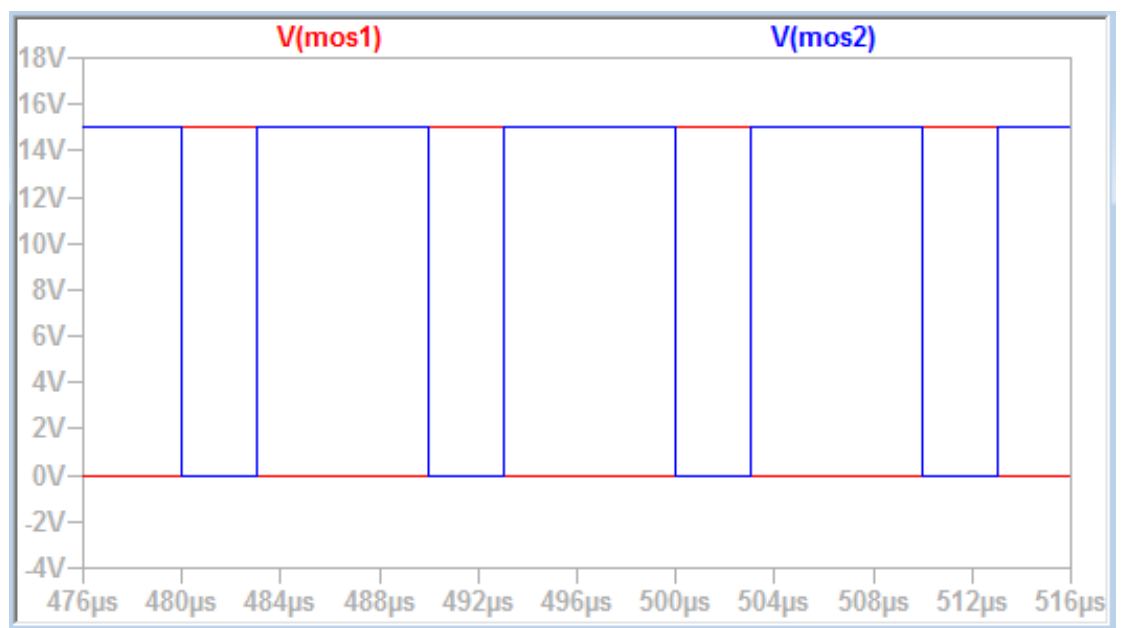

Fig. 7. The voltage across both switches in the synchronous buck

As we can see, the voltage across both switches is the exact opposite of one another. When switch 1 is on, the other switch is off. And we can see the duty cycle of switch 1 is $30 \%$, and the duty cycle of switch 2 is $70 \%$. The output voltage and current of the synchronous buck are shown in Fig. 8.

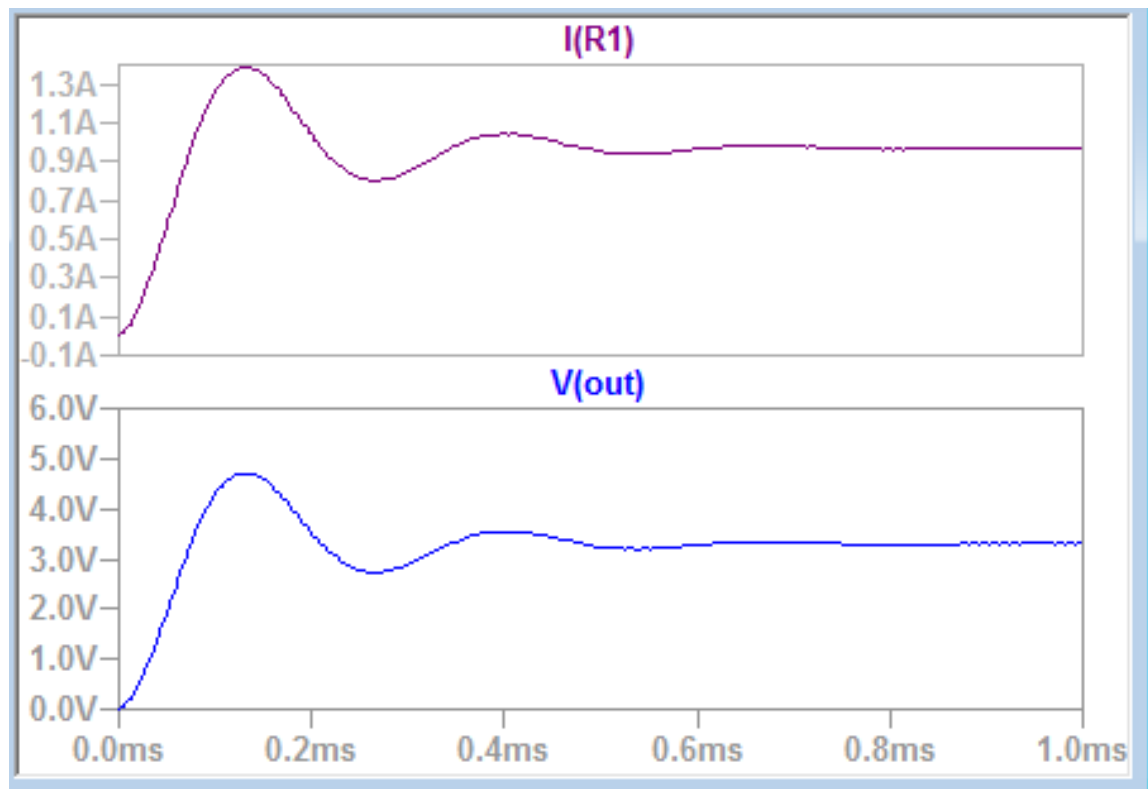

Fig. 8. Output voltage and current of the synchronous buck

As we can see from Fig. 8, the output voltage and current by utilizing synchronous buck are a little higher, and the power losses are lower.

\subsection{Comparison Between Regular Buck and Synchronous Buck Converter}

The output power of both converters is different due to the lower power losses of the synchronous buck converter. Table 2 shows the comparison table of both DC-DC step-down converters. 
Table 2. Comparison of the two different step-down converters

\begin{tabular}{|c|c|c|}
\hline & Output power & Efficiency \\
\hline Regular buck & $3.32 \mathrm{~W}$ & $94.67 \%$ \\
\hline Synchronous buck & $3.61 \mathrm{~W}$ & $96.27 \%$ \\
\hline
\end{tabular}

Based on Table 2, the output power of the synchronous buck is 3.61 watts, and the output power of the regular buck is 3.32 watts, which indicates that by using synchronous buck for low power application, the losses will be lower. In addition, the efficiency of the system when using a synchronous buck converter is higher.

\section{Conclusion}

The two types of buck converters are compared in this research, as well as their design and modeling. The efficiency of the step-down converter can be improved by using an additional MOSFET instead of a diode. In LTSPICE, both approaches' modeling and simulation are provided. According to simulation data, employing a synchronous step-down converter increases the output power of a system with identical components, implying that using a synchronous buck causes fewer losses. The future research will focus on using synchronous buck converters for high-power applications by using IGBT instead of MOSFET.

Author Contribution: All authors contributed equally to the main contributor to this paper. All authors read and approved the final paper.

Funding: This research received no external funding.

Conflicts of Interest: The authors declare no conflict of interest.

\section{References}

[1] G. Zhang, Z. Li, B. Zhang, and W. A. Halang, "Power electronics converters: Past, present and future," Renewable and Sustainable Energy Reviews, vol. 81, pp. 2028-2044, 2018, https://doi.org/10.1016/j.rser.2017.05.290

[2] J. Kreiss, M. Bodson, R. Delpoux, J.-Y. Gauthier, J.-F. Trégouët, and X. Lin-Shi, "Optimal control allocation for the parallel interconnection of buck converters," Control Engineering Practice, vol. 109, p. 104727, 2021, https://doi.org/10.1016/j.conengprac.2021.104727

[3] H. Wang, A. Gaillard, and D. Hissel, "A review of DC/DC converter-based electrochemical impedance spectroscopy for fuel cell electric vehicles," Renewable Energy, 2019, vol. 141, pp. 124-138, https://doi.org/10.1016/j.renene.2019.03.130.

[4] R. Nowakowski and N. Tang, Efficiency of synchronous versus nonsynchronous buck converters, Texas Instruments Incorporated, 2009, https://www.tij.co.jp/jp/lit/an/slyt354/slyt354.pdf\#page=15.

[5] N. Z. Yahaya, K. Begam, and M. Awan, "Experimental analysis of a new zero-voltage switching synchronous rectifier buck converter," IET power electronics, vol. 4, no. 7, pp. 793-798, 2011, https://doi.org/10.1049/iet-pel.2010.0218.

[6] P. Alavi, E. Babaei, P. Mohseni, and V. Marzang, "Study and analysis of a DC-DC soft-switched buck converter," IET Power Electronics, vol. 13, no. 7, pp. 1456-1465, 2020. https://doi.org/10.1049/ietpel.2019.0431.

[7] A. Asghari, "Ultra-high step-down ZVS synchronous buck converter with low switch voltage stress," IET Power Electronics, vol. 13, no. 10, pp. 2039-2048, 2020, https://doi.org/10.1049/iet-pel.2019.1113.

[8] S. Kapat, "Sampling-induced border collision bifurcation in a voltage-mode DPWM synchronous buck converter," IEEE Transactions on Circuits and Systems II: Express Briefs, vol. 66, no. 6, pp. 1048-1052, 2018, https://doi.org/10.1109/TCSII.2018.2866520

[9] A. Yousefiankalareh, M. A. Manoochehri, S. Alireza Khoshnevis and S. R. Surakanti, "Improve the Frequency Identification in SSVEP based BCI Systems with Moving Windows Algorithm," in 2019 6th International Conference on Control, Instrumentation and Automation (ICCIA), IEEE, 2019, https://doi.org/10.1109/ICCIA49288.2019.9030862. 
[10] I. Furukawa and Y. Sugimoto, "A synchronous, step-down from 3.6 V to 1.0 V, 1MHz PWM CMOS DC/DC converter," Proceedings of the 27th European Solid-State Circuits Conference, IEEE, 2001, pp. 69-72, https://ieeexplore.ieee.org/abstract/document/1471336.

[11] A. Balal, M. Herrera, Y. L. Chuang, and S. Balali, "Analysis of Buck, Boost, and Flyback Topologies Using for Active Power Factor Correction," 2021 International Conference on Intelligent Technology, System and Service for Internet of Everything (ITSS-IoE), IEEE, 2021, pp. 1-6, https://doi.org/10.1109/ITSS-IoE53029.2021.9615337.

[12] S. Chakraborty, H.-N. Vu, M. M. Hasan, D.-D. Tran, M. E. Baghdadi, and O. Hegazy, "DC-DC converter topologies for electric vehicles, plug-in hybrid electric vehicles and fast charging stations: State of the art and future trends," Energies, vol. 12, no. 8, p. 1569, 2019. https://doi.org/10.3390/en12081569

[13] Q. Zhao and G. Stojcic, "Characterization of Cdv/dt induced power loss in synchronous buck dc-dc converters," IEEE Transactions on Power electronics, vol. 22, no. 4, pp. 1508-1513, 2007, https://doi.org/10.1109/TPEL.2007.900527.

[14] A. Yousefiankalareh, T. Kamyab, F. Shahabi, E. Salajegheh, H. Mirzanejad and M. M. Masouleh, "Face recognition based on sparse coding using support vector machine classifier," 2021 International Conference on Intelligent Technology, System and Service for Internet of Everything (ITSS-IoE), IEEE, 2021, https://doi.org/10.1109/ITSS-IoE53029.2021.9615322.

[15] J. A. Reyes-Malanche, N. Vázquez, and J. Leyva-Ramos, "Switched-capacitor quadratic buck converter for wider conversion ratios," IET Power Electronics, vol. 8, no. 12, pp. 2370-2376, 2015, https://doi.org/10.1049/iet-pel.2014.0755.

[16] D. Jauregui, B. Wang, and R. Chen, Power loss calculation with common source inductance consideration for synchronous buck converters. Texas Instruments, SLPA009A, June, 2011.

[17] K. Jayaswal and D. K. Palwalia, "Performance analysis of non-isolated DC-DC buck converter using resonant approach," Engineering, Technology \& Applied Science Research, vol. 8, no. 5, pp. 3350-3354, 2018, https://doi.org/10.48084/etasr.2242.

[18] S. Roy, S. Mukherjee, and C. K. Sarkar, "Highly efficient PWM synchronous buck converter with optimized LDMOS," Superlattices and Microstructures, vol. 83, pp. 595-603, 2015, https://doi.org/10.1016/j.spmi.2015.04.010

[19] Z. Iqbal, U. Nasir, M. T. Rasheed, and K. Munir, "A comparative analysis of synchronous buck, isolated buck and buck converter," 2015 IEEE 15th International Conference on Environment and Electrical Engineering (EEEIC), IEEE, 2015, https://doi.org/10.1109/EEEIC.2015.7165299

[20] S. S. Kumar, A. Panda, and T. Ramesh, "A ZVT-ZCT PWM synchronous buck converter with a simple passive auxiliary circuit for reduction of losses and efficiency enhancement," Ain Shams Engineering Journal, vol. 6, no. 2, pp. 491-500 2015, https://doi.org/10.1016/j.asej.2014.10.018.

[21] Y. Bai, "Optimization of power MOSFET for high-frequency synchronous buck converter," Doctorial Disertation, Virginia Tech, 2003, https://vtechworks.lib.vt.edu/handle/10919/28915.

[22] H. Luo, H. Wen, X. Li, L. Jiang, and Y. Hu, "Synchronous buck converter based low-cost and highefficiency sub-module DMPPT PV system under partial shading conditions," Energy Conversion and Management, vol. 126, pp. 473-487, 2016, https://doi.org/10.1016/j.enconman.2016.08.034.

[23] M. Orabi and A. Shawky, "Proposed switching losses model for integrated point-of-load synchronous buck converters," IEEE Transactions on Power Electronics, vol. 30, no. 9, pp. 5136-5150, 2014, https://doi.org/10.1109/TPEL.2014.2363760.

[24] A. Balal and F. Shahabi, "Design a Multiport DC-DC Converter for Hybrid Renewable Nano-grid System," 2021 Fourth International Conference on Electrical, Computer and Communication Technologies (ICECCT), IEEE, 2021, https://doi.org/10.1109/ICECCT52121.2021.9616853.

[25] A. Yousefiankalareh, E. Salajegheh, F. Shahabi, H. Mirzanejad, S. Balali and S. Seddighi, "Reverse Optimizing Consensus of Higher-Order Heterogeneous Linear Multiagent Systems Based on LQR method," 2021 International Conference on Intelligent Technology, System and Service for Internet of Everything (ITSS-IoE), IEEE, 2021, https://doi.org/10.1109/ITSS-IoE53029.2021.9615299.

[26] F. Marvi, E. Adib, and H. Farzanehfard, "Zero voltage switching interleaved coupled inductor synchronous buck converter operating at boundary condition," IET Power Electronics, vol. 9, no. 1, pp. 126-131, 2016, https://doi.org/10.1049/iet-pel.2014.0960.

[27] A. Balal and M. Herrera, "Design a Power Converter to Charge a Hybrid Electric Vehicle," in 2021 IEEE 18th International Conference on Smart Communities: Improving Quality of Life Using ICT, IoT and AI (HONET), IEEE, 2021, https://doi.org/10.1109/HONET53078.2021.9615492. 
[28] Q. Xu, Y. Yan, C. Zhang, T. Dragicevic, and F. Blaabjerg, "An offset-free composite model predictive control strategy for DC/DC buck converter feeding constant power loads," IEEE Transactions on Power Electronics, vol. 35, no. 5, pp. 5331-5342, 2019, https://doi.org/10.1109/TPEL.2019.2941714.

[29] A. Balal, S. Rukh, and S. Balali, "Designing a Dual Active Transformer DC-DC Forward Converter for DC Micro-Grid Applications Using LTSPICE," International Journal of Applied Engineering Research, vol. 16, no. 4, p. 327-331, 2021, https://www.ripublication.com/ijaer21/ijaerv16n4_13.pdf.

[30] S. Chakraborty, M. M. Hasan, I. Worighi, O. Hegazy, and M. A. Razzak, "Performance evaluation of a PID-controlled synchronous buck converter based battery charging controller for solar-powered lighting system in a fishing trawler," Energies, vol. 11, no. 10, p. 2722, 2018, https://doi.org/10.3390/en11102722. 